Article

\title{
The Collapse of the Morandi Bridge in Genoa on 14 August 2018: A Collective Traumatic Event and Its Emotional Impact Linked to the Place and Loss of a Symbol
}

\author{
Nadia Rania *, Ilaria Coppola, Francesco Martorana and Laura Migliorini \\ Department of Education Sciences, University of Genoa, 16126 Genova GE, Italy; \\ ilaria.coppola@edu.unige.it (I.C.); S4622026@unige.it (F.M.); Laura.Migliorini@unige.it (L.M.) \\ * Correspondence: nadia.rania@unige.it
}

Received: 8 October 2019; Accepted: 26 November 2019; Published: 1 December 2019

check for updates

\begin{abstract}
The collapse of the Morandi bridge in Italy, which took place in the summer of 2018, has had enormous emotional, economic, and social consequences for the inhabitants of the area, which are felt throughout the world. As seen in the literature, collective traumatic events increase the experience of insecurity and paranoia, thus increasing the perception of vulnerability. The present work aims to bring out the emotions most experienced by the participants connected to the traumatic event in question, paying attention to the possible solutions to be proposed to local stakeholders from a sustainability perspective, this way favouring community empowerment. The research, carried out with the photovoice technique, involved 30 young adults residing in areas near the event. The results illustrate how the participants experienced mainly feelings of emptiness, vulnerability, and fear as well as anger, despair, and mistrust of the institutions. It was also stressed that the economic and structural hardships hit the inhabitants hard. There have been many concrete solutions identified by the participants: creating a support network, supporting the local economy, and keeping the memory alive. The research and application implications underline the importance of using photovoice within community interventions, a tool that facilitates awareness and active citizenship.
\end{abstract}

Keywords: emotion; collective traumatic event; photovoice; Italy

\section{Introduction}

In recent years, natural or human-caused disasters have affected entire nations not only because of repercussions on the health of those directly involved or residing in these areas but also because of the loss of infrastructure and economic instability, which affects social and environmental systems and community structures [1].

In the present research, we focus on a collective traumatic event that impacted the minds and consciences of many Italian people around world: the collapse of the Morandi bridge in August 2018. This event had a strong emotional impact not only on the inhabitants but also on most who had passed through the area during their lifetime and those who had to cross other bridges around the world in the following days. The collapse of the Morandi bridge had a strong global, emotional effect in the hours and days that followed that was linked not only to the place but also to the loss of a symbol.

The traumatic nature of the bridge collapse was similar to other collective traumatic events, such as natural disasters, including the Indian Ocean tsunami on 26 December 2004 [2], the great East Japan earthquake and tsunami in 2011 [3], several eruptive episodes of El Hierro island in 2011 [4], and the F3 tornado that struck the commercial and civic heart of the community of Goderich, Ontario, Canada, in August 2011 [5] as well as human-caused disasters such as the Sewol Ferry Disaster in 
2019 [6] and terror attacks such as the attack on 11 September 2001 [7]. When these events occur, we refer to collective trauma because a sudden, deflagrating event upsets an entire community at the same time [8], causing invisible internal scars that shape the memories of a community and influence the daily life of each member [9]. If a traumatic event occurs in an individual's life, depending on the seriousness, it results in a deep disturbance in the life of that person; but a collective trauma risks damaging in depth the intricate networks of social relations that are at the base of the existence of a community [10]. As affirmed by Micieli-Voutsinas [7], terror attacks contribute to the overall sentiments of insecurity, paranoia, and a nostalgia for 'safer times' in the same way that the collapse of the bridge has led to a life of insecurity and paranoia linked to infrastructures that are now considered obsolete, and on which the state should have intervened with controls and important maintenance work. Citizens develop a sense of vulnerability with the occurrence of these events, which are outside of rationality and indiscriminately affect everyone. Places and landscapes are transformed into wounded areas [11] from which the population has to start again to create a new sense of belonging and to reconstruct the landscape and heal physical and emotional wounds. In fact, those places will no longer be experienced and perceived as before. Moreover, as underlined by Han et al. [6], these disasters, natural or human-caused, impart tremendous shock and trauma and overwhelming pain throughout the country.

Han et al. [6] stated that manmade disasters are more detrimental to mental health than natural disasters, and that the processing of emotional distress and anger is hampered by a delayed identification of human causes $[12,13]$. When dealing with natural or human-caused disasters that are unexpected and unpredictable, it is implied that a collective or shared sense of place and a sense of the risk of loss will occur in both human and environmental terms [14]. Moreover, disasters have harmful effects on the mental health status of trauma-exposed people. In this regard, the literature has focused mainly on the study of post-traumatic stress [15], and little attention has been dedicated to analyzing the emotional aspects related to developing participation and empowerment. This article aims to focus on how people deal with the consequences of a tragedy, in connection with the place and context of their communities. Particular focus is placed on the emotional toll that working in unique collective trauma related to the collapse of Morandi Bridge landscapes has on participants and on researchers.

To contribute to the traumatic events literature from a community participation perspective, the aims of this study are, through the technique of photography and narration, to elicit the emotional aspects related to a place where a collective trauma has occurred, to propose solutions to local stakeholders to develop individual and community empowerment, and to promote sustainable development among the inhabitants of that place.

\section{The Morandi Bridge Context}

On 14 August 2018, the Genoa community was hit hard by an unpredictable and tragic event, the collapse of the Morandi bridge, which caused the death of 43 people. The Morandi bridge, named after the designer who built it between 1963 and 1967, is also known as the "bridge of conduct" by the company that built it, in the same manner that the "Brooklyn Bridge" is known for the shape that recalls a famous American bridge, the "bridge of Cornigliano" is known for the name of the district that it crosses, or "Bridge Polcevera" is known for the river that flows under it. The bridge was a crucial artery not only for the road network of the city but also for the entire transportation system of the area. The collapse created a deep infrastructural rift that has destabilized an entire city from an economic and emotional point of view. The bridge was the symbol of passage for the city and a symbol of departures from and arrivals to Genoa, and many people travelled over or under the bridge daily to reach their place of work. The city in its various forms, both formal and informal, overcame the first moments of disbelief and despair and promptly activated to overcome the initial emergency situations. This included not only recovering the dead but also assisting displaced people who could not re-enter their homes below the bridge, as the area was considered to be too dangerous. Committees were created to try to represent the point of view of displaced persons and work on several initiatives to obtain funds 
for their benefit, ranging from the creation and sale of "Genoa in the heart" $t$-shirts (with the symbol of the broken bridge and a red heart that unites the parts) at charity evenings, concerts, and marathons, to the introduction of dedicated exhibitions such as "That time on a bridge" with photos and stories linked to the bridge or to the creation of books.

\section{The Use of the Photovoice Technique to Elicit Feelings and Emotional Dimensions}

The photovoice technique was developed in the early 1990s by Caroline Wang et al. [16]. Since its inception, photovoice has gained popularity and has been applied to different disciplines, such as psychology [17-20], education [21-24], and nursing [25,26], and to study particular issues such as those related to parenting, refugees, intercultural relations, and other marginalized groups [27-29].

The photovoice method is a tool of participatory action research (PAR) [30-32] used by researchers to develop community-based research projects. PAR uses arts-based methods [33] that endorse community change and stimulate participants to identify, represent, and develop their communities. According to Chevalier et al. [34], PAR and the photovoice method try to connect science with society for social change. Photovoice is based on Freire's education for critical consciousness theory [35], feminist theory [36], and documentary photography [37].

Photovoice serves three main objectives: (1) enable participants to think about their community's strengths and weaknesses, involving people in an active process of listening and dialogue; (2) promote introspection and critical dialogue about personal and community issues; and (3) reach local stakeholders in the community.

The focus of photovoice is on the everyday life experiences of participants to reveal participants' perspectives, values, and emotions [38]. It is a visual method that uses photos made by the participants to elicit their point of view. The major advantage of these image-based techniques, compared to the more conventional qualitative techniques, is that it allows an individual to represent their own experiences or feelings otherwise difficult to express. Additionally, images play on and arouse emotions; in fact, pictures offer real representations of an existing situation in a way that verbal language sometimes cannot capture. Therefore, photos can be used as an instrument to explore the life experiences of participants, or they become a medium through which participants share thoughts and emotions without the limitation of verbal language [20,39].

According to Manasia [23], through photos, participants expose both objective (e.g., facts and events) and subjective (e.g., emotions and feelings) aspects of their lives. Moreover, depending on the different perspectives, because of the life experiences of each individual, the observer of the photo can give a different interpretation with respect to the intentions of the photographer. As underlined by Harper [40] (2002) and Liebenberg [41] (2018), photos can prompt emotions and thoughts about experiences in ways that narratives alone cannot. Each image has many different "voices" and arouses different feelings and emotions depending on the person who looks and interprets the photo [18]. The significance of photography is not intrinsic to the object itself, rather, it is attributed by those who discuss it. During the initial activities related to photography and collaborative group discussion, participants face serious and sensitive topics that can arouse strong emotions, both positive and negative, such as being upset or frustrated. While these emotions can be considered personal growth, the researcher, however, must have a plan for addressing this situation when it arises.

Furthermore, photovoice is a visual method that, through the use of images, offers the opportunity for participants to propose possible solutions to the issues studied. The participants, through the selection of images, develop their own perspective un a visual way [42]. They observe their community and select objects, persons, or scenes that they believe are important [43]. Therefore, researchers use photovoice because it encourages participants to express and defend the issues that they consider important in the context of their analysis. As stated by Simmonds et al. [28], photovoice involves more than taking pictures and talking about them; it stimulates reflection through thoughts on the issue, the decision to take a specific picture, and the following debate on the picture in the group dimension. 
Therefore, as underlined by Manasia [23], photovoice is a relational methodology, like many qualitative techniques, and its value is related to the development of the relationship among participants and researchers inside the PAR. In fact, photovoice requires that participants take on multiple roles; they are individuals who share their photos that represent their ideas and their feelings about their experiences in the community. Therefore, the participants are also photographers with sensitivity. Because photovoice is a method of PAR, participants have the role of co-researchers who analyze the data collected during the group discussion through the sharing of the photos and the identification of possible solutions to be implemented in that context.

Therefore, according to Keremane et al. [44], the adage "a picture is worth a thousand words" correctly applies to the photovoice technique because the photos and the stories draw out the participants' ideas and emotions about the topic being studied.

\section{Materials and Methods}

\subsection{Participants}

To reach the aim of the research, 30 young Italian adult volunteers ( $90 \%$ females and $10 \%$ males) were involved. They lived in the city of Genoa or in the neighbouring village and used the bridge for their daily transit. The participants had a mean age of 23 years ( $19-40$ years, $\mathrm{SD}=4.47)$. The participants were divided, randomly, into 4 groups of 6-9 members to realize the "SHOWeD" method. The term "SHOWeD" is an acronym that corresponds to the following five questions: What do you See here? What's really Happening here? How does this relate to Our lives? Why does this problem or this benefit exist? What can we Do about this?

The participants took part in a workshop organized to present the purpose of the PAR, the methodology of photovoice, and the basics of the photographic technique. During the workshop, the participants also received information on the use of photovoice images and signed consent forms that allowed the photovoice images to be used in the research. The researchers provided written informed consent to the participants, who were informed that their participation was voluntary. The data collection procedure complied fully with the Research Ethical Code of the Italian Association of Psychology. This study was carried out in accordance with the ethical recommendations of the Declaration of Helsinki and in compliance with the American Psychological Association (APA) standards for the treatment of human volunteers.

During the workshop, the participants were encouraged to think about the event of the Morandi bridge collapse, particularly the emotional and organizational impact on the city where they lived (phase 1). During phase 2, participants had to independently photograph what best represented the theme to them. This phase lasted approximately two weeks. This was followed by a period in which the participants had to select two or three of their photos, print them, and add a comment to each photo. In phase 3, the participants met, and each participant presented his/her photos and explained the meanings of the photos and his/her feelings related to taking the picture. After the group observed all the pictures produced by the participants, they debated them following the "SHOWeD" method [45]. This discussion method allows for a deeper and more critical dialogue about the themes proposed by participants, thereby eliciting their feelings and positions related to the issue.

At the end of the discussion phase, the participants produced 4 billboards, one for each group, that were presented in the following months during a city initiative, planned in the form of a permanent exhibition, with local stakeholders taking part in the inauguration.

\subsection{Data Analysis}

The researchers, through a process of triangulation, analyzed the photos (visual data) with the respective comments (textual data) and the transcripts of the group discussions (textual data), resulting in the emergence of similarities among the objects and content in the photographs. Each participant was assigned an individual code (P1, P2, etc.) and a group code (SG1 = SHOWeD Group, SG2, etc.). 
Recalling the work of [46] Ronzi et al., in Figure 1, we can see the process used by the participants and the researchers, which allowed us to identify and categorize the most frequent topics.

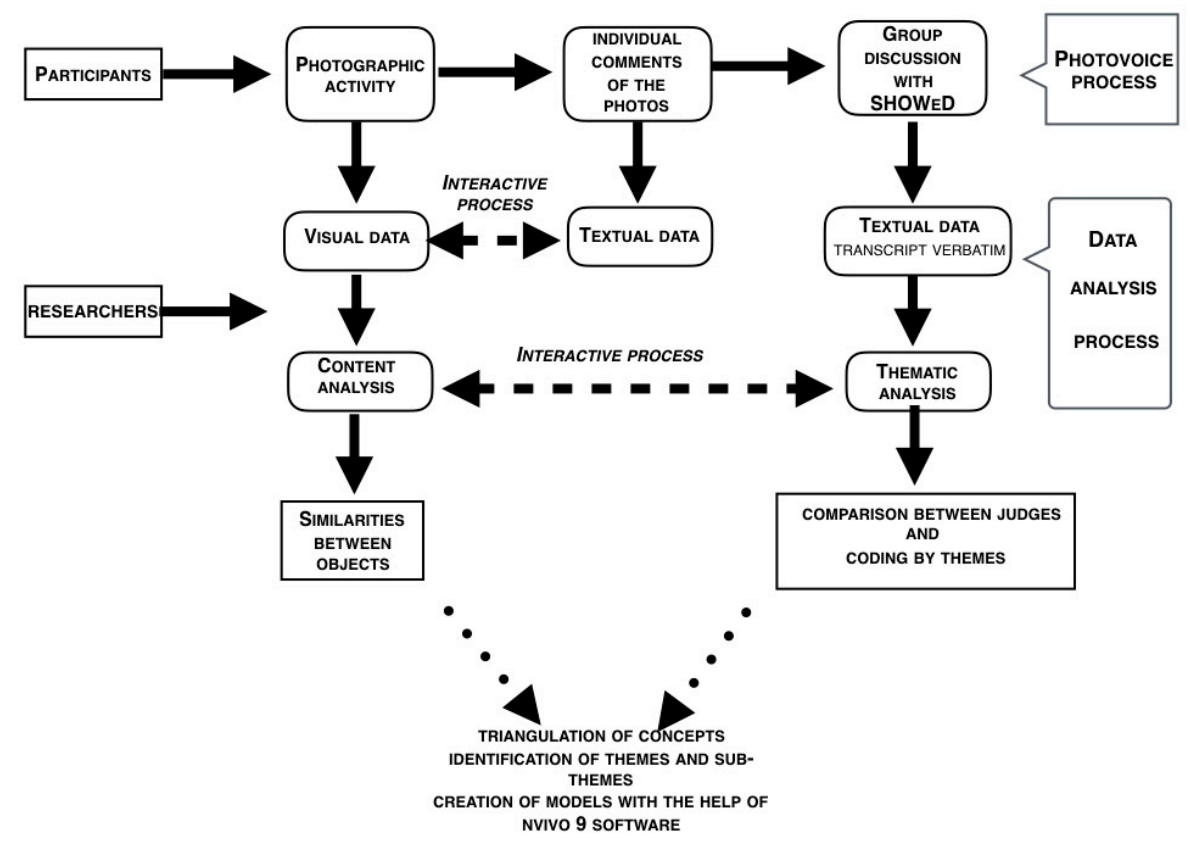

Figure 1. Participants and researchers' data analysis process modified from Ronzi et al. [46].

The categorization process was done by two independent judges who were tasked with identifying the main common issues that emerged through the support of the software Nvivo9 (2010). With the software support, the authors created a model based on grounded theory [47]. The model was composed of nodes, and its labels represented the categories identified by the researchers that exemplified the main themes that emerged.

\section{Results}

The results are presented in subparagraphs according to the categories that emerged from the triangulation of visual and textual data: "emotions after the collapse", "economic and social consequences", and "from trauma to hope". In addition, the most significant photos are presented, and the subcategories and some significant verbalizations are presented for each model.

\subsection{Physical and Emotional Space: Emotions After the Collapse}

From the analysis of the 70 photos presented by participants, most of the participants represented, above all, the image of the broken bridge. Moreover, strong and sometimes contrasting emotions emerged from the individual comments on the photos. Figure 2 shows the point of view of those who had spent time daily on a train under the bridge. In photo 1, a participant expressed awareness of being fortunate by not having suffered in person as well as bewilderment and sadness due to the tragedy of the event.

In the second photo of Figure 2, it emerged that the bridge represented a symbol, particularly for students, who attributed the silence of the bridge as they passed by as a favorable sign that they would not be tested. Today, the same silence assumes different meanings, particularly regarding respect for the dead and the tragedy that occurred.

In Figure 3, the photos, which display a physical void that corresponds to an emotional emptiness, underscore how the event left a sense of emptiness-a surreal presence that in fact replaced a structure that is now internalized-and emotions of anger since the event was perceived as something that could have been avoided. 


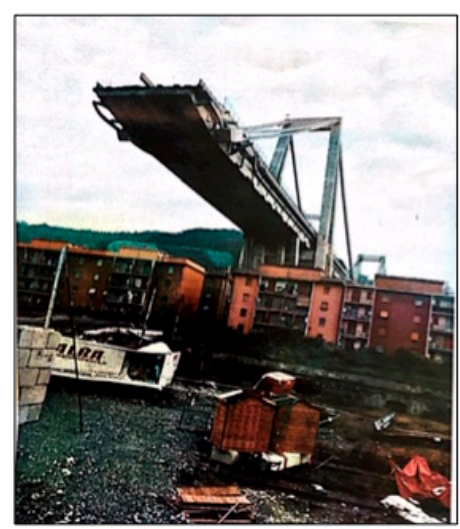

Photo 1

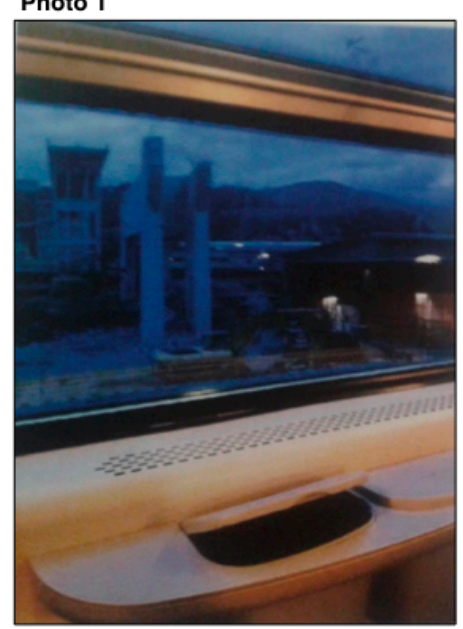

Photo 2

"Passing near that area, on one hand, you feel fortunate to think of how many times you have walked that road without having suffered personally from the damage caused by the collapse, but on the other hand, you have a sense of melancholy and sadness increased by the sight of all the damage that this tragic event has brought about" (P16, SG3).

"For us local students, the Morandi bridge was the interrogation bridge.

During the years of high school passing by the train at this exact point one could hear "Shhh, be silent, because if you talk while passing under the bridge, legend has it that you will get an unexpected oral test from the teachers at school!". After this sentence, silence fell. Today, the feeling is completely different: what catches the eye are the debris and the hanging cables, but one thing has not changed: the silence, which falls every day at this precise point and makes me shudder; it is no longer superstition, it is sadness, bewilderment, respect" (P7, SG1).

Figure 2. The views of the commuters of the train passing under the bridge.


Figure 3. Physical emptiness and emotions.

Finally, in Figure 4, a participant expressed emotions through the gaze of a child inhabitant of the area who remained particularly affected by the tragic event even after some time. 


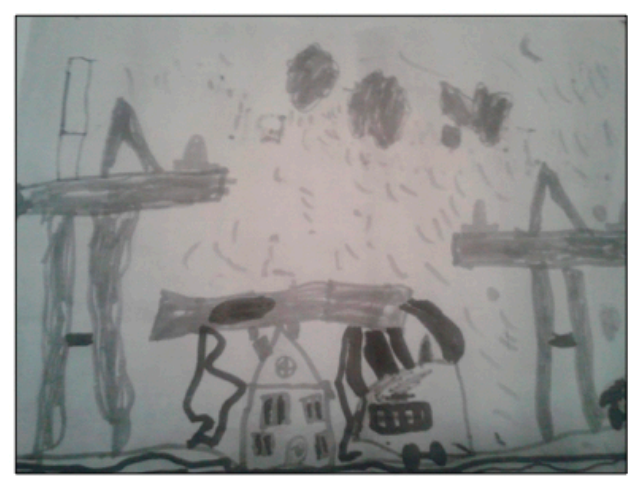

Photo 5
"This photo is about the drawing of a 5-year-old boy: one morning when he woke up, he jumped into my arms and told me that he had dreamed of being on the Morandi bridge and running for save his life during the collapse. In the morning he made this drawing, depicting every single detail, as if he had actually lived that moment in his dream" (P5, SG1).

Figure 4. The voice of children.

Figure 5, which represents the model "emotions after the collapse", presents the main emotions expressed by the participants linked to the collapse of the bridge: physical and inner emptiness, traumatic shock, vulnerability and impotence, fear, anger, desperation, and distrust.

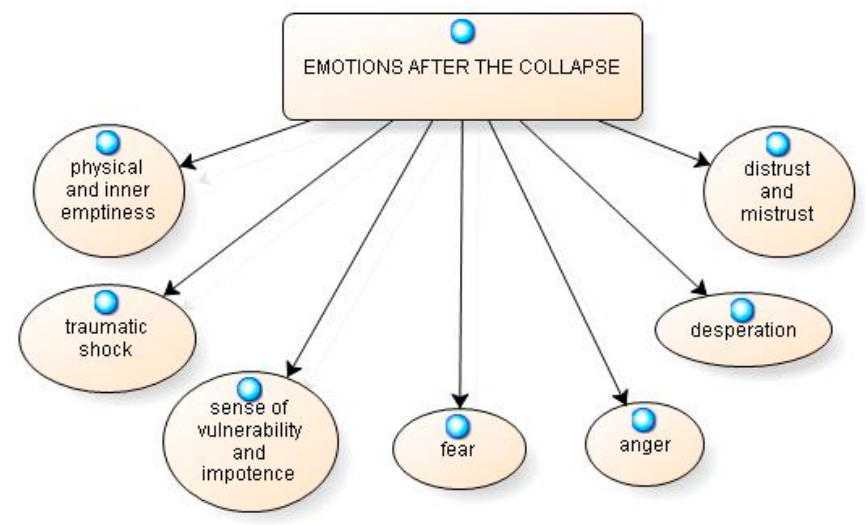

Figure 5. Models of emotions after the collapse.

Many of the participants chose to photograph what is left of the bridge precisely to underline the physical and inner emptiness that the event has caused, especially in those who live in that area: "It's such a surreal thing because it seems that the heaven wanted to take a piece of bridge, because it is incredible that piece of fallen bridge that has left empty" (P17, SG3); "An empty vision, when you look at the bridge, you have a vision of emptiness. Even those who live in that area have been like a block, not being able to move. It has become a ghostly city. The first few days you did not know, nobody was there, nobody wanted to talk about it" (P3, SG 1).

The experience of traumatic shock, caused by a situation perceived as surreal, was still felt by some participants and affected the emotions of children, who felt troubled and posed many questions that were often expressed in the form of drawings. Others reported feeling immobilized in the face of the trajectory of this event:

"Working with children, the weight of the emotions that this tragedy has caused them is really strong. Every day, after three months, these children ask what really happened, what happened to those people under the rubble and if the firefighters managed to save them. The questions often occur in the form of a drawing, so every day we must be prepared for their questions"; (P11, SG2)

"When I saw the news, the very day of the fall, it seemed like a surreal thing that could only happen in the movies, and I was shocked"; (P20, SG3) 
"You see the broken bridge, the fact that you see the bridge so reduced gives me a feeling of absolute silence, of tragedy that leads me to feel immobilized; it still happens to me every time I pass by there". (P21, SG3)

The feeling of shock was sometimes accompanied by a sense of vulnerability and impotence:

"I have seen everything, here it starts, and here it all ends"; (P27, SG4)

"This is the closest point to be in the middle of the void between the two stumps of the bridge. Here, they met the president of the region and the mayor. Here, 43 roses were thrown into the bed of the Polcevera. Here, I spend almost every day, and I feel small, irrelevant and impotent"; (P15, SG2)

"I felt vulnerable, a little baby; I felt powerless". (P17, SG3)

Fear was another of the predominantly experienced emotions and was caused primarily by two aspects: the situation itself, which was experienced as something unexpected by not only the citizens of Genoa but also by all people in Italy, and the thought that loved ones could be involved in the tragedy.

"Genoa did not stop, but Italy stopped. According to me, under those rubble, there is a piece of all Italy because no one expected such a situation, and everyone was speechless but also, at the same time, afraid"; (P24, SG4)

"I thought, oh God, who may have been involved in the accident, and I thought of all the people in Genoa, all the people who lived outside Genoa, who could be involved, and what I found scary is that I should really call everyone because being a pivot point they could be there". (P4, SG1)

Finally, the participants expressed anger, desperation, and distrust towards institutions that did not seem to want to assume any responsibility for the incident and also should have foreseen and avoided this tragedy, as it was not a natural catastrophe but rather the collapse of a structure that was created by man and on which many relied.

"I think that nowadays, it is absurd that many people put us at the hands of others because I am convinced that someone's at fault and that it is the responsibility of the people in power", but they do not take responsibility for all that has happened"; (P28, SG4)

"Seeing all these photos, I also feel a bit of anger, I would say enough, because it was predictable, because they already knew that the bridge was collapsing, and I would say that these victims could have been avoided"; (P25, SG4)

"In my opinion, the absurdity of the tragedy is that a highway fell, not because of a landslide or an explosion, that we relied on, a road infrastructure". (P24, SG4)

The emotions expressed by the participants were not limited to the suffering caused by the collapse alone but included, above all, the immense physical and social consequences that the tragedy caused.

\subsection{Economic and Social Consequences}

Another of the issues raised was linked to economic and social consequences, as seen in Figure 6.

With regard to the category "economic inconvenience" (Photo 6), many participants paid attention to the change suffered by the economy of the area, such as the closure of shops or companies resulting from the closure of the neighbouring streets for the safety of the people and the fear of new collapses: "Going all the way near the bridge, you can see how the collapse of the Morandi bridge has affected the economy of the area. Shops that were previously open all day and full of customers are now forced to stay closed" (P10, SG2). However, "structural inconvenience" (Photo 7) was described as follows: "the situation of the road organization is very serious and disastrous; the road is completely blocked, at peak times there are queues that last for hours" (P16, SG3). 


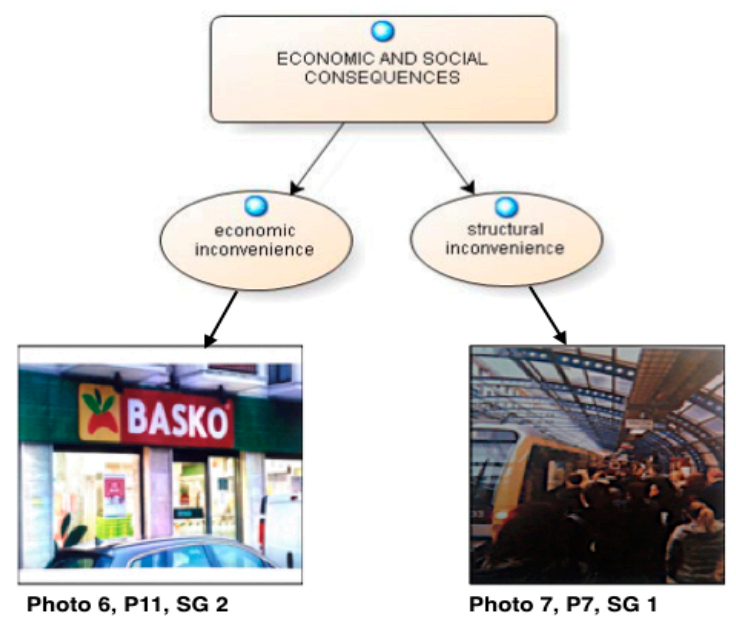

Figure 6. Models of economic and social consequences.

\subsection{From Trauma to Hope: The Collapse of a Symbol and the Rebirth of a Community}

From the analysis of verbalizations, it emerged that many of the participants, overwhelmed by the trauma they experienced and perceived, were unable to propose possible solutions: "Unfortunately, we are powerless in the face of this situation, this tragedy, the bureaucracy. Unfortunately, we cannot do anything. It's a tennis match with sins, and we are the field and the net on which the ball beats" (P27, SG4). Other participants, however, wanted to give voice to rebirth and hope, and they reported, through the photos (Figure 7), the various initiatives related to solidarity that have been introduced throughout the city. They noted these as examples of the determination of a city that does not give up but, from a community point of view, tries to be reborn and faces the tragedy in a collective and supportive way: "the desire, the strength and the determination of a community that, despite being knocked down, wants to be reborn and be strengthened in every possible way" (P22, SG3).

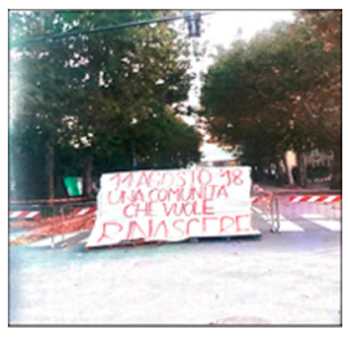

P2, SG1*

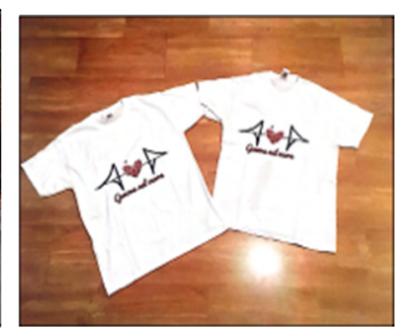

P14, SG2

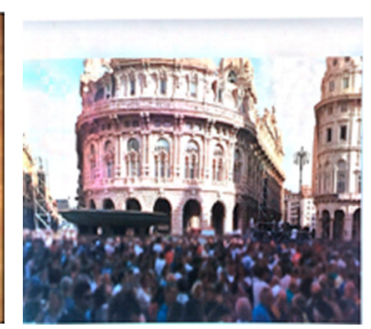

P21, SG3

Figure 7. The rebirth of a community; ${ }^{*}$ translation of the poster: A community that wants to be reborn.

Although feelings of dismay and impotence were predominant in the groups, several concrete solutions emerged for overcoming the trauma and supporting the rebirth of the hard-hit community. The categorization process led to the identification of five dimensions that were presented through the verbalizations of the participants:

- Active citizenship: "Everyone has to work together, participate to do their best, to be heard, we must not sit on our hands with our hands" (P22, SG3);

- Support networks: "You could create a self-help group and support for displaced people and create a network" (P3, SG1);

- Use of public transportation: "To help the road system, our young people could use fewer personal means and more public transportation" (P21, SG3); 
- Support for the local economy: "Surely the citizens, rather than going to buy in large supermarkets, could go and buy in small shops, especially those in the areas around the bridge, to support them" (P20, SG3);

- Keep the memory alive: "Even if the city has already started moving, my fear is that people may forget this moment, and instead, I would like this moment and the people involved to be remembered" (P21, SG3).

As we can see, the categories that emerged included proposed solutions that are anchored in reality, that must be addressed in everyday life, and that involve the individual and the whole community.

\section{Discussion}

Through the use of the narratives and collective rituals that one experiences in a photovoice activity, it is possible to transform a tragic event into an element of empowerment, thus giving meaning to suffering and reinforcing social bonds [48]. As underlined by Hikichi [3], the community level informal socializing and social participation experienced during the photovoice activity can buffer the impact of cognitive decline in the aftermath of a disaster. Group resilience, in fact, affects the emotional, behavioral, and psychological aspects of the group in relation to the traumatic situation that must be addressed in order to positively direct individual and community resources. We, therefore, start from the premise that communities are competent and able to identify the resources needed to face challenges positively and adapt to a traumatic collective event. Collective resilience and individual and community empowerment are mainly based on the dimensions of participation, mastery, and involvement [49].

Analysis of the results showed that, among the participants, a sense of emptiness, impotence, and fear prevailed because of the traumatic shock of this event. The event upset the entire community, generating despair and mistrust in the institutions that were responsible for the protection and safety of all who used the bridge daily. Furthermore, several studies emphasized the potential of photovoice to generate knowledge because it allows for the exploration of participants' views, emotions, feelings, and practices and their ideas for problem solving [44].

The fact that the trauma occurred in a symbolic space and in a space used by all adds to the trauma and, in fact, destroys any sense of security. This finding is in line with previous research suggesting that the loss of familiar landscapes and routines, rather than the loss of individual property or personal injury, could be a better predictor of the psychological impacts suffered by disaster [50].

Consistent with Silver and Grek-Martin [5], the participants expressed feelings of pain, grief, loss, frustration, uncertainty, and unbelief while simultaneously expressing intense feelings of union, purpose, and identity because of sharing an experience of disruption and disorientation. This occurs because people undergoing a process of disorientation and reorientation adapt to the changing states of "normal" at individual and community levels.

Shang [51] pointed out that when a catastrophe occurs, the quality of support for survivors, rather than the quantity of support provided, is critical; through this photovoice activity experience, we could highlight how this represents a quality intervention aimed at small groups of people who are active within their community.

With regard to the discomfort arising from this event, many of the participants residing in the area and in neighbouring areas pointed out that traffic has intensified, and many of the shops have been forced to close because they are located in areas at risk near the bridge, thus causing considerable structural and economic inconvenience as evidenced by United Nations Office for Disaster Risk Reduction [52].

Nevertheless, some of the participants found it difficult to identify possible solutions, as they were still overwhelmed by the trauma and their feelings of dismay, which is consistent with Yu [53]. However, many participants, through the use of photos, wanted to highlight the determination of a community that is ready to act to revive itself through gestures of solidarity and fundraising events. In addition, the participants mentioned numerous solutions, including those requiring their personal involvement and the involvement of the entire community. This was especially evident for those 
who lived closest to the trauma landscape, which is in agreement with Ruiz et al. [4]. Indeed, those who were nearest the event activated themselves more. In fact, people with higher place attachment report greater social and political involvement in their communities [54], working together to achieve a desired outcome. As affirmed by Anton and colleagues [55], developing place attachment to one's home and local area is linked with many positive health and community participation outcomes.

In effect, during the photovoice activity, the participants' use of the visual art of the photos and the visual memory involved in making the photos contributed to their motivation to find solutions despite the possible emotional distress experienced in rethinking and re-experiencing the tragic event [56]. Active participation in choosing solutions and in planning and design may allow citizens the opportunity to take control of their environment when in mourning for real or symbolic losses. The solutions identified by the participants were an attempt to reconnect with a sense of security; the reclaiming of the site thus becomes part of the individual and community recovery process. Therefore, participation in creating and rebuilding the physical place of mourning, including developing ideas and solutions for problems that emerge, may also help the recovery of the survivors.

Through discussion and the identification of solutions, the participants in the photovoice activity expressed emotions and feelings that were very deep and connected to the place of the tragedy. This allowed them to rework the trauma and place themselves in a condition of active participation in the process of designing and tackling the problems to be resolved, thereby enabling them to face the collective trauma dimension in a positive and constructive way.

\section{Conclusions}

The participants in the research, through the use of photographic techniques and individual and group analysis of the photos, were able to express and provide meaning regarding the emotions they experienced most in relation to the collapse of the bridge as well as the main problems and possible solutions for those problems. According to Ciolan et al. [22], applying visual methods allows participants to communicate their point of view, their needs, and their emotional states associated with the topic under debate and develop individual and community empowerment.

Furthermore, through the photovoice activity, the participants developed social resilience in a disaster context. Resilience is defined in the literature as an absorptive, adaptive, and transformative capacity or the ability of social entities or social processes to forecast, respond to, and recover from disasters [57]. Indeed, because photovoice is a reflexive method, it contributed to developing social resilience in the participants through the discussion of their emotions and the search for potential solutions. Moreover, as underlined by Aslam Saja [57], developing social resilience to disasters among citizens has been highlighted as a key factor in disaster risk reduction. The use of photovoice can support this effort both before and after a critical situation.

As suggested by Thordardottir et al. [58], although knowledge concerning trauma recovery and implementation of psychosocial support worldwide has increased, it is still necessary to work hard to understand how to improve and make psychosocial support more efficient as well as how to recover from and prevent development of problems over the long term. In addition to psychological first aid, which includes physical and emotional support and connections with social networks, the photovoice method can help citizens develop a collective or shared sense of place and belonging to the context.

Future research should focus more on how awareness can be an instrument of active participation in change; furthermore, new research could further verify how the photovoice is a useful tool to support people exposed to trauma, enabling them to face the collective trauma dimension in a positive and constructive way.

Furthermore, using the photovoice method, we as researchers faced second-hand trauma. As underlined by Dominey-Howes [1] (p. 1), "Direct personal vicarious trauma is where I experienced trauma associated with witnessing devastation making a professional separation from my objective subjects impossible". All types of catastrophes are devastating and have significant physical, material, economic, and psychosocial impacts on affected individuals, communities, and on the researchers 
who study these phenomena. Therefore, when research is done on traumatic content, the researcher is also involved. It is not realistic to imagine the researcher as an objective scientist and detached from the content and experience of his/her research [1]. However, participating in the emotions of the participants allowed us to penetrate deeply into the research and to relive with them the trauma faced, rendering us citizens of the city affected by this terrible disaster. Reflecting as a group of researchers and writing an article on this subject allowed us to give voice to the citizens as well as give voice, in part, to us as researchers and citizens involved in this dramatic event. Undertaking this PAR effort regarding the collapse of the Morandi bridge allowed us to face the collective trauma of the participants and our fellow citizens on the one hand, and to experience the vicarious trauma as professionals involved in a research and support process with the participants on the other hand. Some authors [59] have suggested the relevance of mindfulness practice those exposed to traumatic disasters; in fact, researchers can work out vicarious trauma through mindfulness practice.

From a practical perspective, as underlined by Han [6], our findings indicate that mental health professionals and policymakers must pay more attention to encourage the advancement of sustainability and provide social support or related social welfare services to people exposed to trauma.

Author Contributions: Conceptualization, N.R. and L.M.; methodology, N.R. and I.C.; software, I.C. and F.M.; investigation, N.R. and I.C.; data curation, N.R. and I.C.; writing-original draft preparation, N.R., F.M. and I.C.; writing-review and editing, N.R. and I.C.; supervision, N.R. and L.M.

Funding: This research received no external funding.

Acknowledgments: We would like to thank all the participants for their availability and interest in this research, in which they took an active part in their sharing emotions and thoughts on such a delicate subject.

Conflicts of Interest: The authors declare no conflicts of interest.

\section{References}

1. Dominey-Howes, D. Seeing 'the dark passenger' e Reflections on the emotional trauma of conducting post-disaster research. Emot. Space Soc. 2015, 17, 55-62. [CrossRef]

2. Kaewlai, R.; Meennuch, W.; Srisuwan, T.; Prasitvoranant, W.; Yenarkarn, P.; Chuapetcharasopon, C. Imaging in Tsunami Trauma. J. Med. Ultrasound 2009, 17, 1-8. [CrossRef]

3. Hikichi, H.; Aida, J.; Matsuyama, Y.; Tsuboya, T.; Kondo, K.; Kawachi, I. Community-level social capital and cognitive decline after a natural disaster: A natural experiment from the 2011 Great East Japan Earthquake and Tsunami. Soc. Sci. Med. 2018, in press. [CrossRef]

4. Ruiz, C.; Hernández, B. Emotions and coping strategies during an episode of volcanic activity and their relations to place attachment. J. Environ. Psychol. 2014, 38, 279-287. [CrossRef]

5. Silver, A.; Grek-Martin, J. "Now we understand what community really means": Reconceptualizing the role of sense of place in the disaster recovery Process. J. Environ. Psychol. 2015, 42, 32-41. [CrossRef]

6. Han, K.M.; Park, J.Y.; Park, H.E.; An, S.R.; Lee, E.H.; Yoon, H.K.; Ko, Y.H. Social support moderates association between posttraumatic growth and trauma-related psychopathologies among victims of the Sewol Ferry Disaster. Psychiatry Res. 2019, 272, 507-514. [CrossRef]

7. Micieli-Voutsinas, J. An absent presence: Affective heritage at the National September 11th Memorial and Museum. Emot. Space Soc. 2017, 24, 93-104. [CrossRef]

8. Doutheau, C.; Sailhan, M. Le reactions émotionnelles dans les catastrophes. In Encyclopédie Médico Chirurgicale-Psychiatrie; Encyclopedie: Paris, France, 1987; Volume 2, pp. 300-314.

9. Lopez, C. The Struggle for Wholeness: Addressing Individual and Collective Trauma in Violence-Ridden Societies. Explore 2011, 7, 303-313.

10. Frankenberg, E.; Nobles, J.; Sumantri, C. Community Destruction and Traumatic Stress in Post-Tsunami Indonesia. J. Health Soc. Behav. 2012, 53, 498-514. [CrossRef]

11. Till, K. Wounded cities: Memory-work and a place-based ethics of care. Polit. Geogr. 2012, 31, 3-14. [CrossRef]

12. Morgan, C.; Bhugra, D. Principles of Social Psychiatry, 1st ed.; John Wiley \& Sons: New York, NY, USA, 2010. 
13. Norris, F.H.; Friedman, M.J.; Watson, P.J.; Byrne, C.M.; Diaz, E.; Kaniasty, K. 60,000 disaster victims speak: Part I. An empirical review of the empirical literature, 1981-2001. Psychiatry 2002, 65, 207-239. [CrossRef] [PubMed]

14. Magee, L.; Handmer, J.; Neale, T.; Ladds, M. Locating the intangible: Integrating a sense of place into cost estimations of natural disasters. Geoforum 2016, 77, 61-72. [CrossRef]

15. Schnurr, P.P.; Green, B.L. Trauma and Health: Physical Health Consequences of Exposure to Extreme Stress, 1st ed.; American Psychological Association: Washington, DC, USA, 2004.

16. Wang, C.; Burris, M.A. Empowerment through photo novella: Portraits of participation. Health Educ. Q. 1994, 21, 171-186. [CrossRef] [PubMed]

17. Brunsden, V.; Goatcher, J. Reconfiguring Photovoice for Psychological Research. Ir. J. Psychol. 2007, 28 , 43-52. [CrossRef]

18. Rania, N.; Migliorini, L.; Rebora, S.; Cardinali, P. Photovoice and interpretation of pictures in a group discussion: A community psychology approach. Qual. Res. Psychol. 2015, 12, 382-396. [CrossRef]

19. Migliorini, L.; Rania, N. A qualitative method to "make visible" the world of intercultural relationships: The photovoice in social psychology. Qual. Res. Psychol. 2017, 14, 131-145. [CrossRef]

20. Saita, E.; Tramontano, M. Navigating the complexity of the therapeutic and clinical use of photography in psychosocial settings: A review of the literature. Res. Psychother. 2018, 21. [CrossRef]

21. Hernandez, K.; Shabazian, A.N.; McGrath, C. Photovoice as a Pedagogical Tool: Examining the Parallel Learning Processes of College Students and Preschool Children through Service Learning. Creat. Educ. 2014, 5, 1947-1957. [CrossRef]

22. Ciolan, L.; Manasia, L. Reframing Photovoice to Boost Its Potential for Learning Research. Int. J. Qual. Methods 2017, 16. [CrossRef]

23. Manasia, L. From Community to Individual. Re-Thinking Photovoice Methodology for Education Research. EpSBS Fut. Acad. 2017, 450-459. [CrossRef]

24. Rania, N.; Migliorini, L.; Rebora, S. Reflections on teaching qualitative methods through team-based learning: An exemplification by Photovoice. Qual. Rep. 2017, 22, 2006-2016.

25. Burke, D.; Evans, J. Embracing the Creative: The Role of Photo Novella in Qualitative Nursing Research. Int. J. Qual. Methods 2011, 10, 164-177. [CrossRef]

26. Leipert, B.; Anderson, E. Rural Nursing Education: A Photovoice Perspective. Rural Remote Health 2012, 12, 2061. [PubMed]

27. Rania, N.; Migliorini, L.; Rebora, S.; Cardinali, P. Enhancing critical dialogue about intercultural integration: The Photovoice technique. Int. J. Intercult. Relat. 2014, 41, 17-31. [CrossRef]

28. Simmonds, S.; Roux, C.; Ter Avest, I. Blurring the boundaries between photovoice and narrative Inquiry: A narrative photovoice methodology for gender-based research. Int. J. Qual. Methods 2015, 14, 33-49. [CrossRef]

29. Rania, N.; Migliorini, L.; Cardinali, P.; Rebora, S. Giving a face to immigration and integration processes: The use of Photovoice with Italian young adults. Qual. Rep. 2015, 20, 780-798.

30. Lewin, K. Action research and minority problems. J. Soc. Issues 1946, 2, 34-46. [CrossRef]

31. Montero, M. Teoría y Práctica de la Psicología Comunitaria: La Tension Entre Comunidad y Sociedad, 1st ed.; Paidós: Barcelona, Spain, 2003.

32. Rania, N.; Brameri, A.; Migliorini, L.; Gandolfo, E. From Group development to intervention: Applying participatory action research. in Italy. In Participatory Action Research. Principles, Approaches and Applications, 1st ed.; Calder, J., Foletta, J., Eds.; Nova: Hauppauge, NY, USA, 2018; pp. 233-250.

33. Coemans, S.; Wang, Q.; Leysen, J.; Hannes, K. The use of arts-based methods in community-based research with vulnerable populations: Protocol for a scoping review. Int. J. Educ. Res. 2015, 71, 33-39. [CrossRef]

34. Chevalier, J.M.; Buckles, D. Participatory Action Research: Theory and Methods for Engaged Inquiry, 1st ed.; Routledge: Abingdon-on-Thames, UK, 2013.

35. Freire, P. Education for Critical Consciousness, 1st ed.; Continuum: New York, NY, USA, 1973.

36. Smith, D. The Everyday World as Problematic: A Feminist Sociology, 1st ed.; University of Toronto Press: Toronto, ON, Canada, 1987.

37. Spence, J. Cultural Sniping: The Art of Transgression, 1st ed.; Routledge: London, UK, 1995.

38. Holm, G. Photography as a performance. Forum Qual. Soc. Res. 2008, 9. [CrossRef] 
39. Uhrig, M.K.; Trautmann, N.; Baumgärtner, U.; Treede, R.D.; Henrich, F.; Hiller, W.; Marschall, S. Emotion elicitation: A comparison of pictures and films. Front. Psychol. 2016, 7, 180. [CrossRef]

40. Harper, D. Talking about pictures: A case for photo elicitation. Vis. Stud. 2002, 17, 13-26. [CrossRef]

41. Liebenberg, L. Thinking Critically About Photovoice: Achieving Empowerment and Social Change. Int. J. Qual. Methods 2018, 17. [CrossRef]

42. Mitchell, C.; DeLange, N.; Moletsane, R.; Stuart, J.; Buthelezi, T. Giving a face to HIV and AIDS: On the uses of photo-voice by teachers and community health care workers working with youth in rural South Africa. Qual. Res. Psychol. 2005, 2, 257-270. [CrossRef]

43. Hodgetts, D.; Chamberlain, K.; Radley, A. Considering Photographs Never Taken During Photo-production Projects. Qual. Res. Psychol. 2007, 4, 263-280. [CrossRef]

44. Keremane, G.B.; McKay, J. Using PhotoStory to capture irrigators' emotions about water policy and sustainable development objectives: A case study in rural Australia. Action Res. 2011, 9, 405-425. [CrossRef]

45. Wang, C. Youth participation in photovoice as a strategy for community change. J. Community Pract. 2006, 14, 147-161. [CrossRef]

46. Ronzi, S.; Pope, D.; Orton, L.; Bruce, N. Using photovoice methods to explore older people's perceptions of respect and social inclusion in cities: Opportunities, challenges and solutions. SSM Popul. Health 2016, 2, 732-744. [CrossRef]

47. Glaser, B.G.; Strauss, A.L. The Discovery of Grounded Theory: Strategies for Qualitative Research, 1st ed.; Aldine de Gruyter: Chicago, IL, USA, 1967.

48. Keats, P.A. Multiple text analysis in narrative research: Visual, written, and spoken stories of experience. Qual. Res. 2009, 9, 181-195. [CrossRef]

49. Peterson, N.A.; Zimmerman, M.A. Beyond the individual: Toward a nomological network of organizational empowerment. Am. J. Community Psychol. 2004, 34, 129-145. [CrossRef]

50. Cox, R.S.; Perry, K.M. Like a fish out of water: Reconsidering disaster recovery and the role of place and social capital in community disaster resilience. Am. J. Community Psychol. 2011, 48, 395-411. [CrossRef]

51. Shang, F.; Kaniasty, K.; Cowlishaw, S.; Wade, D.; Ma, H.; Forbes, D. Social support following a natural disaster: A longitudinal study of survivors of the 2013 Lushan earthquake in China. Psychiatry Res. 2019, 273, 641-646. [CrossRef] [PubMed]

52. United Nations Office for Disaster Risk Reduction Terminology on Disaster Risk Reduction. Available online: http://www.unisdr.org/we/inform/terminology (accessed on 13 March 2019).

53. Yu, A.F. "Where we wanna be": The role of structural violence and place-based T trauma for street life-oriented Black men navigating recovery and re-entry. Health Place 2018, 54, 200-209. [CrossRef] [PubMed]

54. Mesch, G.S.; Manor, O. Social ties, environmental perception, and local attachment. Environ. Behav. 1998, 30, 504-519. [CrossRef]

55. Anton, C.E.; Lawrence, C. Home is where the heart is: The effect of place of residence on place attachment and community participation. J. Environ. Psychol. 2014, 40, 451-461. [CrossRef]

56. Hass-Cohen, N.; Bokoch, R.; Findlay, J.C.; Witting, A.B. A four-drawing art therapy trauma and resiliency protocol study. Arts Psychother. 2018, 61, 44-56. [CrossRef]

57. Aslam Saja, A.M.; Teo, M.; Goonetilleke, A.; Ziyath, A.M. An inclusive and adaptive framework for measuring social resilience to Disasters. Int. J. Disaster Risk Reduct. 2018, 28, 862-873. [CrossRef]

58. Thordardottir, E.B.; Gudmundsdottir, B.; Petursdottir, G.; Valdimarsdottir, U.A.; Hauksdottir, A. Psychosocial support after natural disasters in Iceland-implementation and Utilization. Int. J. Disaster Risk Reduct. 2018, 27, 642-648. [CrossRef]

59. Eriksen, C.; Ditrich, T. The relevance of mindfulness practice for trauma-exposed disaster researchers. Emot. Space Soc. 2015, 17, 63-69. [CrossRef]

(C) 2019 by the authors. Licensee MDPI, Basel, Switzerland. This article is an open access article distributed under the terms and conditions of the Creative Commons Attribution (CC BY) license (http://creativecommons.org/licenses/by/4.0/). 